\title{
Relato de experiência: estudando a Xenofobia sob o viés da Alfabetização Científica e Tecnológica, na Educação de Jovens e Adultos
}

\author{
Daniela Maria Weber* \\ Eniz Conceição Oliveira** \\ José Cláudio Del Pino ${ }^{* * *}$
}

\begin{abstract}
Resumo
Este relato de experiência apresenta uma proposta de aprendizagem através da Alfabetização Científica e Tecnológica, baseada na tríade CTS - Ciência, Tecnologia e Sociedade. Trata de um estudo sobre a Xenofobia com a Educação de Jovens e Adultos, através de leituras de notícias em jornais e sítios eletrônicos, envolvendo casos com brasileiros que vivem fora do Brasil e de imigrantes que moram no Brasil. Como resultados constatou-se um maior envolvimento e autonomia dos estudantes em relação a proposta, disposição em falar sobre o tema e maior aproximação com os conteúdos envolvidos, como o trabalho com mapas e as migrações contemporâneas.
\end{abstract}

Palavras-chave: Alfabetização Científica e Tecnológica; Educação de Jovens e Adultos; Xenofobia.

\section{Experience report: studying Xenophobia under the approach of Scientific and Technological Literacy in Youth and Adult Education}

\begin{abstract}
This case report presents a learning proposal through Scientific and Technological Literacy, based on the STS program - Science, Technology and Society. It consists of a study on Xenophobia within the Youth and Adult Education context through reading of news, on newspapers and websites, involving Brazilians who live abroad as well as immigrants. As a result, it has been found a larger involvement and autonomy of the students towards the proposal, willingness to talk about the subject and a higher approximation to the related syllabus, such as working with maps and contemporary migrations.

Keywords: Scientific and Technological Literacy; Youth and Adult Education; Xenophobia.
\end{abstract}

\section{Apresentação}

Celulares como companhia diária. Acesso constante às redes sociais. Estamos sempre conectados. Estas são afirmações cotidianas que não espantam a mais ninguém. Se a sociedade tem nas tecnologias uma 'parceira de todas as horas', o que tem feito a escola para se adaptar a esses tempos? Aquino (2007) afirma que estar na escola não garante uma aprendizagem de qualidade, pois na maior parte das salas de aula o que se repete são situações rotineiras, ano após ano. $\mathrm{O}$ autor reforça o descompasso que encontramos nos muitos ambientes escolares. O resultado? Alunos menos motivados em relação à vida escolar e resultados cada vez menores nos índices educacionais.

A comprovação de que o modelo de escola que surgiu na Modernidade, e que em muitos espaços ainda usamos, já não cabe mais na sociedade atual (SIBILIA, 2012). Se há pouco interesse pela escola atual, há de se fazer algo. É preciso dar sentido aos anos que dedicamos à escolarização. Nesse sentido é que se desenvolvem

*Endereço Eletrônico: daniweber364@ gmail.com

***Endereço Eletrônico: eniz@ univates.br

****Endereço Eletrônico: jose.pino@univates.br as disciplinas focadas na Alfabetização Científica e Tecnológica, baseada na tríade CTS - Ciência, Tecnologia e Sociedade.

Este relato de experiência tem por objetivo apresentar uma proposta de ensino na perspectiva da Alfabetização Científica e Tecnológica, em uma turma da Educação de Jovens e Adultos - EJA, no Ensino Fundamental, de uma escola pública municipal no Estado do Rio Grande de Sul (RS). A EJA dessa escola é dividida em dois módulos, que juntos correspondem aos anos finais do Ensino Fundamental. Os estudantes moram próximos à escola, que está localizada na periferia da cidade ${ }^{1}$, em um bairro com diversas carências sociais e índice econômico-financeiro baixo. Ao todo, correspondem à 50 estudantes que, como característica da modalidade, alternam períodos de maior assiduidade, com outros de infrequência.

A EJA atende estudantes com mais de quinze anos que não concluíram o Ensino Fundamental. Estes procuram a modalidade por diversos motivos, como não se sentirem à vontade nos espaços em que estavam - muitas vezes devido 
à distorção idade-série, ou então por necessidades a partir da inserção do mercado de trabalho, seja ele formal ou informal. Ou ainda devido à possibilidade de concluírem os estudos em um período mais curto, além de ser uma forma de socialização, pois a escola é também um local para o encontro de amigos e uma possibilidade para novas amizades (SALES; PAIVA, 2014).

A EJA se constitui dessa diversidade geracional. Isto é, em um mesmo ambiente de estudos estão adolescentes-jovens, com idades entre 15 e 18 anos, mas também os jovens-jovens com idades entre 19 e 24 anos, os jovens adultos entre 25 e 29 anos, os adultos e até mesmo os idosos (FERREIRA, 2015). Esses jovens, em maioria estavam em outras turmas do Ensino Regular e por vários motivos, entre eles a repetência e os problemas de indisciplina, agora estão na EJA (BRUNEL, 2004). Os adultos são em maioria trabalhadores durante o dia, pessoas que já constituíram sua própria família e que possuem em comum com esses jovens, a escolaridade incompleta. Ambos estão nesse espaço escolar, alguns afastados por mais tempo, outros sequer saíram da escola, apenas trocaram de turno. É preciso pensar a docência na modalidade de forma diferenciada, cujas metodologias contemplem esses grupos geracionais de forma significativa (FERREIRA, 2015; GUEIRAL, 2013).

Levando em conta os motivos que fazem com que esses estudantes procurem a EJA, já se justifica a constituição de um jeito próprio de trabalho com a modalidade, com conteúdos e metodologias diferenciadas. Pensar a docência na EJA e o uso das tecnologias como meio para envolvê-los a partir dos seus interesses foi o ponto de partida para a realização dessa prática de ensino, apresentada aqui como relato de experiência. Envolvemos a Alfabetização Científica e Tecnológica como metodologia de trabalho a partir do tema "Xenofobia", considerando-o como uma das possibilidades de ensino na modalidade. $\mathrm{Na}$ sequência apresentamos uma breve revisão bibliográfica sobre a Alfabetização Científica e Tecnológica a partir da perspectiva CTS - Ciência Tecnologia - Sociedade, informações sobre outras experiências de ensino na perspectiva CTS, além de apresentar o tema motivador da prática, qual seja, a Xenofobia.

\section{A Alfabetização Científica e Tecnológica}

A ciência e a escola estão marcadas em sua história como restritas a determinados grupos sociais, qual seja, os privilegiados economicamente. Com o advento da proposta de que a Escola deve ser para todos, a própria concepção de Ciência precisou ser revista. Se já não cabe aos espaços escolares a expectativa de formar cientistas, compete à Escola a formação de cidadãos que relacionam os dados estudados aos fatos que nos cercam no cotidiano.

Chassot (2003a, p. 71) alerta de que, cabe ao professor recriar, reapresentar a ciência, isto é, fazer ver o seu verdadeiro "papel científico". Através da reflexão que faz sobre a forma com que escrevemos, o autor citado também reflete sobre as mudanças recentes em relação ao uso do computador e o nosso vínculo com essa ferramenta. Questiona a própria profissão de professor, que permanece da mesma forma estrutural, entre tantas outras profissões que surgiram e desapareceram. Alerta, que o "professor informador", não terá mais espaço nas escolas, precisando ser substituído pelo "professor formador" (p. 82-83) - aquele que ensina a partir do cotidiano, que estimula o estudante a desenvolver-se, o que ele chama de "ensino sujo" (CHASSOT, 2003a, p. 98). Isto é, o ensino que sai do contexto da sala de aula e perpassa a realidade dos espaços, que não tem receio de envolver-se. Que é prático e real. Só assim teremos uma nova concepção de Escola, com sua real função, qual seja, a de selecionar as informações disponíveis, para de fato ser uma "transformadora crítica do conhecimento" (Ibidem, p. 87) e não apenas uma reprodutora de conhecimentos inúteis.

O ensino pela perspectiva da Alfabetização Científica e Tecnológica é uma possibilidade que visa um estudo de qualidade. Com efetiva aprendizagem para a cidadania, considerando que partimos de atividades problematizadoras e da ideia de que o indivíduo usará essa ciência, logo, faz sentido pensar sobre a mesma (SASSERON; CARVALHO, 2011).

Assim, a Alfabetização Científica está ligada a estudantes e professores conscientes dos seus papeis na escola, onde ambos buscam um aprender que tenha sentido à vida. Aprendizagens integrais e constantes, não apenas durante o período escolar, esquecendo conceitos e fórmulas após isso. É o "saber ler a linguagem em que está escrita a natureza" (CHASSOT, 2003b, p. 91), mas que também se afasta do que o autor chama de "[...] um analfabeto científico aquele incapaz de uma leitura do universo" (p. 91). Ou seja, busca combater um ensino pautado na reprodução de fórmulas e conceitos, sem a compreensão de seu entorno. 
Considerando que a ciência não é estática e sim, provisória (SASSERON; CARVALHO, 2011), este tipo de ensino baseado no decorar não faz mais sentido para o momento tecnológico em que vivemos. Na perspectiva de Demo (2010, p. 37),

Educação e alfabetização não são sinônimos. A alfabetização aponta para o sentido propedêutico (de iniciação), ao passo que a educação sinaliza o aspecto formativo. Ambos os olhares são fundamentais, razão pela qual os colocamos juntos: precisamos, na escola e na universidade, trabalhar o lado da alfabetização (introduzir os alunos no mundo do conhecimento científico), bem como caprichar na face formativa da pesquisa.

A responsabilidade de uma formação ampla, envolvendo significado aos acontecimentos, despertando nos estudantes o interesse pelo que de fato ocorre no mundo é dos espaços escolares. É necessário que se ensine pela pesquisa e não pela transmissão de conhecimento e o professor é ativo nesse processo, instigando a curiosidade e o desejo de saber mais. Como profissional, precisa tomar para si a prática da autoria, produzindo seus materiais, não sendo apenas transmissor de práticas já executadas. Assim, estará de fato contribuindo para a construção de conhecimento (DEMO, 2010).

Outra justificativa para o uso da Alfabetização Científica está na ação dos professores, que em muitos momentos encontra dúvidas em relação aos caminhos a seguir, considerando as mudanças da própria educação e da sociedade. Nesse sentido, Leão (2014, p. 74) alerta:

Atualmente, percebe-se que os educadores não conseguem educar para a realidade. Frente a esta problemática constata-se a necessidade de adequação das práticas educativas para que seja um processo de leitura e interpretação de linguagens construídas por pessoas para explicar o mundo a sua volta, entender ciência e tecnologia de forma contextualizada. Desta forma, os estudantes serão estimulados a construir seus próprios significados. Ao promover a AC [Alfabetização Científica] por meio das práticas de ensino adotadas, o educador estará contribuindo para o desenvolvimento da sociedade, pois quanto maior o número de cidadãos alfabetizados cientificamente, melhores serão as condições de vida da população.

$\mathrm{O}$ que se destaca pela perspectiva da $\mathrm{AC}$, de acordo com o autor citado, está na melhoria da qualidade de vida. Guiados pela preocupação com as condições de vida e com o envolvimento no espaço escolar, se encontram outros estudos, outras experiências pedagógicas que são capazes de apresentar caminhos para a docência a partir da perspectiva CTS. Bocasanta, Wandere, Knijnik (2016) apresentam em sua investigação o quanto os estudantes da EJA percebem a presença da ciência e da tecnologia do dia-a-dia, assim como o fazem em relação à matemática, aos números. As autoras explicam o quanto os estudantes anseiam pelo uso da informática nas escolas:

[...] levados a pensar o acesso à ciência e tecnologia como uma necessidade e um direito, passam a enunciar que querem fazer parte dessas tramas, que precisam aprender mais sobre computação, que se ressentem por entenderem que o governo não coloca a educação - e por conseguinte uma melhor aparelhagem da escola para ensinar mais sobre tecnologia - em primeiro lugar (BOCASANTA; WANDERE; KNIJKIK, 2016, p. 88).

A informática é apresentada pelos estudantes como uma necessidade de inserção social, cabendo à escola pública e, consequentemente ao Governo, sua implantação através de equipamentos e profissionais que permitam esta interação digital. Também para Pacheco e Barros (2013, p. 6) o uso de tecnologias é parte do cotidiano e deve fazer parte das atividades escolares pois "[...] possibilitam a aprendizagem ativa do aluno ao permitir-lhe se sentir mais envolvido com os conceitos à medida que estes fazem uso da informática educativa para desenvolver suas teorias". São ferramentas, para que as aulas se aproximam mais das atividades cotidianas, que são permeadas pelas tecnologias computacionais.

Outra experiência de ensino a partir da perspectiva CTS foi feita por Leão (2014), em sua pesquisa que resultou na dissertação de Mestrado. Naquela investigação e seguindo uma proposta de Alfabetização Científica, o estudo de Química foi pensado a partir da relação com a alimentação, comprovando ser uma possibilidade para um maior interesse dos estudantes, pois considera o cotidiano como meio para o estudo.

$\mathrm{Na}$ experiência pedagógica aqui retratada, o tema de estudos é a Xenofobia. Para tanto, convém destacar que por Xenofobia considera-se: "aversão às pessoas e coisas estrangeiras" (AMORA, 2009, p. 782), que são as ações realizadas contra imigrantes, 
através de atos hostis e não simpáticos à sua presença nos países que os acolhem. Envolvem, por exemplo, negativas de emprego, constrangimentos e atos de violência física, moral ou psicológica.

Ferreira (2016) apresenta um estudo sobre as políticas internacionais para imigração na Europa e de como estas influenciam o fluxo mundial de pessoas, identificado atualmente como uma "crise migratória" (p. 88). Também destaca como tarefa para os países que se tornam asilos para os refugiados, "[...] gerir o orgulho nacional e limitar os preconceitos" (FERREIRA, 2016, p. 103), pois são esses sentimentos que motivam as ações citadas anteriormente.

Conhecidos alguns referenciais que envolvem a Alfabetização Científica e Tecnológica e a justificativa para a sua aplicabilidade nos espaços escolares, destacamos a relação dos conhecimentos científicos com as situações cotidianas. Também identificamos outras pesquisas e propostas de ensino através da tríade CTS e apresentamos o conceito de Xenofobia, tema desse relato de experiência. Na sequência, está a descrição da experiência pedagógica e a sua avaliação.

\section{Descrição da experiência}

Um exemplo de experiência com Alfabetização Científica e Tecnológica aconteceu no ano de 2015, durante as atividades docentes com a Educação de Jovens e Adultos - EJA a partir da área das Ciências Humanas, que envolve História, Geografia e Ensino Religioso. Foram utilizados casos reais de crimes de Xenofobia através de reportagens vinculadas aos meios de comunicação.

A recorrência de casos noticiados em um jornal de circulação estadual, foram o motivador para a seleção, por parte da professora, das notícias disponibilizadas aos estudantes para leitura. Também foram feitas buscas em sítios eletrônicos, objetivando casos de notabilidade internacional e que envolvessem outros lugares do planeta. São exemplos de manchetes das notícias discutidas que envolviam o Rio Grande do Sul à época: "Haitianos: racismo camuflado", "Coiotes já ganharam R\$ 185 milhões com o transporte ilegal", "Falta de coordenação dificulta acolhida", todas publicadas durante o mês de maio de 2015. Lidas as reportagens durante uma das aulas, compartilhamos as leituras e conversamos sobre o assunto na mesma noite, através de comparações e da identificação de outros casos, seja de repercussão internacional ou da comunidade local, que eram de conhecimento dos estudantes.

A proposta era a de sensibilizar para a violência dos atos. No encontro seguinte, retomamos as notícias lidas e refletimos sobre as personagens envolvidas e seus posicionamentos. Nos casos de Xenofobia, o objetivo era problematizar como pensam/sentem os nativos que recebem os imigrantes e o porquê destes migrarem para outros países. Refletimos sobre os atos de violência praticados e sua repercussão.

$\mathrm{Na}$ terceira etapa do trabalho ocorreu a produção escrita, quando redigimos uma síntese das reportagens comentadas, incluindo um posicionamento do estudante. Nesse momento já havíamos estudado o conceito de Xenofobia, qual seja, o de aversão àquele que é estrangeiro (AMORA, 2009). Ao propor que conhecessem outros casos e, assim, identificassem a amplitude dos crimes, realizamos o quinto momento do projeto: utilizamos o laboratório de informática para pesquisar sobre casos de Xenofobia contra brasileiros que vivem em outros países. Após as pesquisas, os casos foram mais uma vez socializados e registrados no caderno.

Por se tratar de uma turma da Educação de Jovens e Adultos com vários níveis de escrita, essa socialização aconteceu de diversas formas. Inicialmente propus que fosse oralmente, para o coletivo. Aos que não se sentiram à vontade para tal exposição, oportunizou-se a explanação diretamente para a professora, oralmente ou então na forma de síntese, por escrito no caderno.

Com a pesquisa desenvolveram-se também habilidades no uso do computador, pois os estudantes precisam dominar os softwares dos navegadores da internet, localizar as reportagens, ler e certificar-se de que se trata de um caso verídico. Após, se prepararam para a socialização, que deveria constar a fonte de onde a reportagem foi extraída, assim como a data de sua postagem.

Buscando exemplificar e refletir sobre a xenofobia a partir de exemplos cotidianos, outra discussão feita foi a que envolveu os motivos da vinda de haitianos para o Brasil, especificamente para a região em que a escola está situada, no interior do Rio Grande do Sul. Constatou-se que a região tem recebido haitianos que migram em busca de emprego, principalmente nas indústrias da alimentação e construção civil, que exigem menor escolaridade e que possuem rotatividade maior de trabalhadores. Também identificamos as condições de vida no próprio Haiti, após as catástrofes naturais que sofreram. Com isso, levantamos outro 
questionamento, que é o do preconceito dos brasileiros com esses imigrantes e como eles vêm sendo recebidos pelos governos, empresas e população em geral (SCHMIDT, PICCININI, VOLKMER, 2016).

Como primeiro apontamento em relação aos resultados da experiência relatada, cabe destaque o envolvimento dos estudantes com as tarefas que lhes foram propostas. Este interesse vai ao encontro do que esclarecem Oliveira e Kaercher (2016, p. 14) quando escrevem sobre o ensino de Geografia para as juventudes, de que

O que chama atenção dos jovens, e principalmente na aula de Geografia, é quando a informação passa a ter sentido e se transforma em conhecimento, mais ainda se o conhecimento se aplica a situações cotidianas e se transforma em sabedoria. E este processo não se compreende como tarefa de fácil resolução. Há que efetuar o planejamento de aulas com muita atenção, para que o que for trabalhado possa de fato corroborar na construção do conhecimento e sua consequente aplicação em situações reais.

Acreditamos que ao contemplar uma temática atual, relacionada aos noticiários e ao cotidiano, principalmente quando citamos os haitianos alocados no Brasil e no município dos estudantes, instigamos a refletir sobre a Geografia do cotidiano, aquela que os afeta, que está nos entornos, que se aproxima do dia a dia. Propor o ensino por meio das Tecnologias e de temáticas condizentes com a realidade permite dar sentido para a Escola, oferecendo significados a esses espaços muitas vezes marcados pela falta de realismo entre o ensino e a sociedade.

Junto às leituras e estudos sobre os motivos das imigrações, trabalhamos a localização espacial, por meio da Cartografia. Questão de elevado significado, mas que precisou ocupar outros espaços e outras reflexões junto ao ensino de Geografia (LOPES, 2015). Trazer a Cartografia para o estudo da Xenofobia ocorreu pois era preciso visualizar no mapa o porquê de alguns deslocamentos e notícias serem mais frequentes, como por exemplo, os casos de naufrágio de barcos com imigrantes na costa italiana, ou então de mortes nos desertos da fronteira entre Estados Unidos e México, que eram relatados pelos estudantes como outros exemplos de migrações.

O trabalho com mapas físicos auxiliou na compreensão desses deslocamentos, aproximando a atividade de leitura de mapas do ensino escolar.
Desvinculando-se da ideia de uma cartografia com "[...] formas rígidas e convencionais cartesianas para tentar demonstrar por mapas solidificados, ou seja, prontos e acabados as representações vigentes (LOPES, 2015, p. 106) para um estudo que faça relação com o cotidiano, em que o mapa analisado faço sentido, tenha significados reais - neste caso, estudar casos de Xenofobia a partir das migrações contemporâneas.

Sobre o uso da Cartografia nos espaços escolares, Lopes (2015, p. 106) vai além e justifica que o " $[. .$.$] distanciamento e repulsa de professores$ e alunos em trabalhar com a Cartografia, [acontecia] visto que ela não se associava com o cotidiano. Não se via nela uma utilidade para as experiências diárias, que pudesse representá-los”. A reorganização da Geografia e a retomada da Cartografia como parte do processo de ensino e de aprendizagem, parte também do trabalho docente e da capacidade de fazer relações, dando significados aos símbolos expostos e superando "[...] o estudo do mapa pelo mapa. [...] Não um simples manusear de mapas, mas estes carregados de valores, de comunicação, de percepções, de singularidades." (LOPES, 2015, p. 107)

Visando esclarecer a experiência relatada, identificamos um passo-a-passo das tarefas realizadas e que estão listadas a seguir. Juntas duraram aproximadamente um mês de trabalho, mas variaram na aplicabilidade de acordo com a frequência dos estudantes e das habilidades dos mesmos:

1 - Seleção, pela professora, das notícias em jornal e sítios eletrônicos para leitura com os estudantes;

2 - Socialização e discussão das notícias;

3 - Escrita de síntese das notícias;

4 - Introdução ao conceito de Xenofobia;

5 - Pesquisa de casos de Xenofobia contra brasileiros que residem fora do Brasil (uso do laboratório de informática);

6 - Estudo sobre a vinda de haitianos para o Brasil e para a região.

Sobre as atividades propostas no laboratório de informática da escola, importa informar que foram realizadas em duplas e trios, devido ao número de estudantes e a quantidade de computadores disponíveis nas noites em que utilizamos o laboratório. Embora disponha de doze máquinas, em média estavam disponíveis de oito a dez computadores, pois os demais necessitavam de manutenção. Nos encontros, além da professora 
titular da disciplina nos acompanhava um professor de informática, auxiliando os estudantes no uso das ferramentas de pesquisa, bem como no manuseio do próprio computador, como o uso correto dos programas, do mouse, botões esquerdo/direito e teclas de atalho.

$\mathrm{O}$ incentivo ao uso do laboratório, acompanhado do professor de informática, se faz para aproximar os estudantes do que propõem Bocasanta, Wandere e Knijnik (2016) de que mesmo trabalhando em duplas ou pequenos grupos, existe a utilização do espaço, reforçando "como uma necessidade e um direito" (p. 88) a este uso, ao pertencimento aos espaços digitais a partir da escola.

A escolha por reportagens de jornal e da pesquisa em sites da internet se fez para aproximar os conteúdos, dos assuntos abordados pelas mídias e visualizados no cotidiano. Afinal, como nos lembram Oliveira e Kaercher (2016, p. 14),

Vive-se na sociedade da rapidez e da informação, isto é inegável. Em tempos nos quais as informações percorrem o mundo em velocidades incríveis e os jovens acompanham com muita facilidade estas transformações e esta velocidade, o professor de Geografia deve saber como reinventar sua prática pedagógica.

A busca por notícias em jornais e a pesquisa prévia em sites que poderiam ser opções de busca para os estudantes coloca o professor na perspectiva de um pesquisador, de um provocador de reflexões. Não há espaço para a mera reprodução de informação quando se propõe o ensino de Geografia baseado na contemporaneidade.

Ao propor que os estudantes escrevessem sobre o que estudávamos, a partir das leituras feitas e das discussões que aconteciam, nos aproximamos do que propõe Demo (2010, p. 52) de que:

O aluno não está condenado a copiar coisa copiada. Pode também, dentro de suas limitações naturais, ensaiar textos científicos, com o objetivo de se tornar capaz de produção própria, o que permite que continue aprendendo e se atualizando a vida toda.

As considerações do autor se encontram também com os objetivos da própria EJA, de proporcionar aprendizagens ao longo da vida, onde $o$ aprender se faça constantemente (FERREIRA, 2015; GUEIRAL, 2013).

A proposta de pesquisa foi bem aceita junto aos alunos e, segundo Oliveira e Del Pino (2015) está de acordo com a perspectiva CTS, pois segue a abordagem de um tema social e as etapas identificadas:

Nos cursos CTS, de maneira geral, a organização se dá segundo uma abordagem interdisciplinar do ensino de ciências. [...] A partir dos temas sociais se organiza a proposta de abordagem de conteúdos fundamentais para a organização do conhecimento numa área específica. A abordagem dos temas sociais se estrutura na adoção de uma sequência de etapas: uma questão social é introduzida; uma tecnologia relacionada ao tema social é analisada; o conteúdo científico é definido em função do tema social e da tecnologia introduzida; a tecnologia correlata é estudada em função do conteúdo apresentado; a questão social original é novamente discutida (OLIVEIRA; DEL PINO, 2015, p. 3).

Seguindo as indicações dos autores, cabe ressaltar que: a) a questão social tratada nessa experiência foi a violência contra estrangeiros; b) a tecnologia analisada foram as reportagens de jornal e as disponíveis na Internet; c) o conteúdo científico em foco foi a Xenofobia, mas outros foram também envolvidos, como o gênero textual reportagem, os meios de comunicação digital, a imigração, a violência, e a localização espacial por meio de mapas; d) a tecnologia aprofundada foi a pesquisa através da Internet e consequentemente, o uso correto do computador; e) a retomada da questão social foi feita quando analisamos o caso dos haitianos no Brasil.

\section{Considerações Finais}

Ao apresentar esse Relato de Experiência, propusemos socializar uma prática docente de estudo do tema Xenofobia na Educação de Jovens e Adultos. Não se trata de uma receita de como trabalhar determinado conteúdo e sim, um exemplo que de como envolver os estudantes em um conceito da Geografia e sua vinculação com o entorno. Destacamos o protagonismo dado aos estudantes quando eles realizaram a busca por reportagens sobre o que consideravam Xenofobia e a proposta de escuta, a partir das reflexões que faziam. O espaço escolar apareceu como um local de discussão da realidade em que estão inseridos imigrantes e emigrantes, refletindo diretamente na maneira como agimos quando somos alvo de 
preconceito ou de quando somos nós, os agentes causadores do mesmo.

Reparamos que através da proposta houve Alfabetização Científica, pois os estudantes compreenderam a complexidade da temática e a perceberam como um problema, uma questão atual que é, ao mesmo tempo, tão distante e tão próxima de nós, brasileiros (OLIVEIRA; DEL PINO, 2015).

Destaque para os sentimentos dos estudantes durante o estudo, a partir das relações de amizade e de coleguismo com imigrantes haitianos e da compreensão do movimento migratório internacional pelo qual passaram. Também problematizamos os motivos que os levaram a sair de sua terra natal e a opção pelo Brasil e pelo Rio Grande do Sul. Enfatizamos o sentimento de indignação dos estudantes quanto aos casos de Xenofobia contra brasileiros que vivem fora do Brasil.

Como dificuldades dos estudantes, destacamos a atividade de pesquisa na internet e interpretação das notícias com relação ao conceito de Xenofobia, exigindo a interação constante do professor. Trata-se da relação de construção do conhecimento, em um processo de parceria entre estudante e professor. Como pontos positivos, houve uma melhor compreensão do mapa mundi, pois várias vezes o utilizamos para marcar as rotas dos envolvidos nas notícias estudadas e a reflexão sobre a imigração na região em que estamos.

Muitos estudantes se mostraram mais dispostos a conversar sobre o tema durante as aulas, pois queriam socializar as notícias encontradas, sendo este outro ponto relevante dessa experiência. Sabe-se que o estudante da EJA muitas vezes tem receio de falar sobre o que já sabe ou do que aprendeu, devido aos vários desencontros que já teve com a instituição escolar (BRUNEL, 2004; FERREIRA, 2015). Proporcionar momentos em que são os protagonistas da aprendizagem, são possibilidades de devolver a autonomia em relação ao aprender durante a vida (DEMO, 2010).

Como professores, identificamos que a educação na perspectiva da Alfabetização Científica e Tecnológica é uma possibilidade de destaque no meio educacional, pois descentraliza $\mathrm{o}$ ato de ensinar e de aprender. Durante o período em que esse foi o tema principal das aulas, ou seja, aproximadamente um mês, foi perceptível um maior envolvimento e entusiasmo por parte dos estudantes que foram, de fato, protagonistas do processo educacional.

\section{Nota}

1 Município do Vale do Taquari, com 78.486 habitantes, conforme dados do Instituto Brasileiro de Geografia e Estatística - IBGE. Disponível em $<$ http://www.cidades.ibge.gov.br/xtras/temas.php? lang $=\& \operatorname{codmun}=431140 \&$ idtema $=130 \&$ search $=$ ri o-grande-do-sul|lajeado|estimativa-da-populacao2015-> Acesso em: 26 Ago. 2016.

\section{Referências}

AMORA, Antônio Soares. Minidicionário Soares Amora da língua portuguesa. 19. Ed. São Paulo: Saraiva, 2009.

AQUINO, Julio Groppa. Instantâneos da escola contemporânea. Campinas, SP: Papirus, 2007.

BOCASANTA, Daiane M.; WANDERE, Fernanda; KNIJKIK, Gelsa. Educação de jovens e adultos e os conhecimentos tecnocientíficos: analisando as relações entre ciência, tecnologia e matemática. Horizontes, v. 34, número temático, p. 81-92, dez. 2016.

BRUNEL, Carmen. Jovens cada vez mais jovens na educação de jovens e adultos. Porto Alegre:

Mediação, 2004.

CHASSOT, Attico. Alfabetização científica: questões e desafios para a educação. Ijuí: UNIJUÍ, 2003a.

Alfabetização Científica: uma possibilidade para a inclusão social. Revista Brasileira de Educação em Ciências. Rio de Janeiro. n. 22. p. 89100, Jan/Fev/Mar/Abr. 2003b. Disponível em: http://www.scielo.br/scielo.php?pid=S141324782003000100009\&script=sci_arttext\&tlng=pt. Acesso em 31/03/2015.

DEMO, Pedro. Educação e Alfabetização Científica. Campinas, SP: Papirus, 2010.

FERREIRA, Lorene Dutra Moreira e. Juvenilização na Educação de Jovens e Adultos de Ouro Preto/MG: Trajetórias e perspectivas dos estudantes mais jovens. 2015. 122f. Dissertação (Mestrado em Educação) - Universidade Federal de Ouro Preto, Mariana-MG, 2015. 
FERREIRA, Susana. Orgulho e Preconceito: A resposta europeia à crise de refugiados. Relações Internacionais. n. 50, p. 87-107, junho de 2016.

GUEIRAL, Ana Figueiredo. Estou na EJA. E agora? Critérios para a transferência de jovens "do diurno" para "o noturno". 2013. 55f. Trabalho de Conclusão (Graduação em Pedagogia) Universidade Federal do Rio Grande do Sul. Porto Alegre, 2013.

LEÃO, Marcelo Franco. Ensinar química por meio de alimentos: possibilidades de promover Alfabetização Científica na Educação de Jovens e Adultos. 2014. 191f. Dissertação (Mestrado em Ensino) - Centro Universitário Univates. Lajeado, 2014.

LOPES, Marcos Piter. Conhecimento, Educação e Ensino: elementos constituintes na construção do saber geográfico. Revista Brasileira de Educação em Geografia, Campinas, v. 5, n. 10, p. 88-113, jul./dez., 2015.

OLIVEIRA, Eniz Conceição; DEL PINO, José Claudio. O ensino na perspectiva CTSAE. Aula da disciplina Fundamentos da Alfabetização Científica e Tecnológica - Univates, Lajeado, 2015.
PACHECO, José Adson D.; BARROS, Janaina V. O Uso de Softwares Educativos no Ensino de Matemática. Diálogos: Revista de Estudos Culturais e da Contemporaneidade. $\mathrm{N}^{\circ}$ 8, p. 5-13, 2013.

SALES, Sandra Regina; PAIVA, Jane. As muitas invenções da EJA. Arquivos Analíticos de Políticas Educativas. Dossiê EJA II (2014). v. 22 n 58, p. 119, 30 de junho de 2014. Disponível em: < http://epaa.asu.edu/ojs/article/view/1740/1308>. Acesso em: 16 out. 2015.

SASSERON, Lucia Helena; CARVALHO, Ana Maria Pessoa de. Alfabetização científica e tecnológica: uma revisão bibliográfica. Investigações em Ensino de Ciências. V. 16(1): p. 59-77, 2011.

SCHMIDT, Alice Krämer Iorra; PICCININI, Marta Luisa; VOLKMER, Márcia Solange. O acesso à educação aos imigrantes haitianos em uma escola pública de Arroio do Meio. Signos. Ano 37, n 2, p. 25-39, 2016.

SIBILIA, Paula. Redes ou paredes: a escola em tempos de dispersão. Rio de Janeiro: Contraponto, 2012.

\section{Sobre os autores}

Daniela Maria Weber é licenciada em História (2010) e Mestra em Ensino (2016) pela Universidade do Vale do Taquari. Professora de História para a Educação de Jovens e Adultos na rede pública municipal e das séries finais do Ensino Fundamental na rede privada.

Eniz Conceição Oliveira possui graduação em Química - Licenciatura pela UFRGS (1987) Mestrado (1999) e Doutorado (2004) em Química pela UFRGS. É professora titular da Universidade do Vale do Taquari UNIVATES e realiza pós-doutoramento no Departamento de Educação e Psicologia da Universidade de AveiroPortugal.

José Cláudio Del Pino possui graduação em Licenciatura em Química (1975), e em Química Industrial (1975) pela PUCRS, Mestrado em Ciências Biológicas-Bioquímica (1984) e Doutorado em Engenharia de Biomassa (1994) pela UFRGS. Possui pós-doutorado pela Universidade de Aveiro-Portugal (2004). Atualmente é professor associado da UFRGS e docente da Universidade do Vale do Taquari (UNIVATES).

Recebido em junho de 2017.

Aprovado em março de 2018. 